\title{
ELIGIBILITY
}

\section{GUIDELINES FOR MANUSCRIPT SUBMISSION}

At least one author must be a member of the NAREA.

\section{SUBMISSION}

Four copies of the manuscript, including one original copy, submitted after May 31, 1998, should be sent to:

\author{
Harry M. Kaiser, Incoming Editor, ARER \\ Department of Agricultural, Resource, and Managerial Economics \\ 349 Warren Hall \\ Cornell University \\ Ithaca, NY 14853-7801
}

Submissions by electronic mail to hmk2@cornell.edu will also be accepted. A manuscript should be sent as an attachment in either Microsoft Word or WordPerfect format. Journal information, including guidelines for manuscript submission, is available at the ARER's home page URL: http://www.halcyon.com/uconn/ARER.html.

\section{COVER LETTER}

Indicate that the material has not been offered for publication or published in a similar form elsewhere, and so far as the author(s) knows, does not infringe upon other published material protected by copyright.

\section{TITLE PAGE AND ABSTRACT}

On the first page, list the title of the paper, the author(s), their title(s), department(s), institution(s), and complete address(es). On the next page, list the title of the paper, an abstract not to exceed 100 words, and five or fewer key words describing the content of the manuscript. The author(s)' identification should not be repeated in the abstract or on other pages of the manuscript.

\section{TEXT PREPARATION}

The manuscript should be typed on $812^{\prime \prime} \times 11^{\prime \prime}$ standard weight white paper, and all material, including references and footnotes, should be double-spaced with margins of at least $1 \frac{1 / 4}{4}$ inch. Use 12 point Times or a similar font style and size.

\section{STYLE}

Follow the Chicago Manual of Style, 14th ed., University of Chicago Press.

\section{TABLES}

Each table should be on a separate page with all material double-spaced. Titles should be short and descriptive.

\section{FIGURES}

After a manuscript is accepted, send hard copy originals of figures ready for photographic reproduction. Each figure should be placed on a separate page, and each must have a title. Text within the figures should be in Times or a similar font.

\section{MATHEMATICAL NOTATION}

Use only essential mathematical notation. Avoid using the same character for both superscripts and subscripts, using capital letters as superscripts and subscripts, and using overbars, tildes, carets, and other modifications of standard type. Use your word processor's character formatting for bold (vectors and matrices), italic (variables), superscript, and subscript styles, and use Symbol font whenever possible for typesetting mathematical notation.

\section{FOOTNOTES}

In general, the use of footnotes should be avoided. Number all notes consecutively and type double-spaced on separate pages at the end of the manuscript.

\section{REFERENCES}

List references alphabetically and unnumbered on a separate page or pages at the end of the manuscript with the heading "References." List only those actually cited. Cite references in the text by the name(s) of the author(s) and the year of the publication. If there is more than one source in a given year, then use, for example, 1981a, 1981b. A style sheet on references and citations is available from the editor or through the ARER's home page.

\section{PAGE CHARGE}

A page charge is billed to the department or agency after the article is accepted for publication. 
